\title{
Glycemic Index and Postprandial Blood Glucose Response to Japanese Strawberry Jam in Normal Adults
}

\author{
Tomoka KurotoBi ${ }^{1}$, Kimiaki FuKUHARA ${ }^{1, *}$, Hiroko INAGE $^{2}$ and Shuichi KImURA ${ }^{2}$ \\ ${ }^{1}$ Fruits Processing Research Center, Aohata Co., Ltd., 1-1-25, Tadanouminakamachi, \\ Takehara, Hirosima 729-2392, Japan \\ ${ }^{2}$ Graduate School of Human Life Science, Showa Women's University, \\ 1-7, Taishido, Setagaya-ku, Tokyo 154-8533, Japan
}

(Received November 12, 2009)

\begin{abstract}
Summary We investigated in 30 healthy adults the glycemic index (GI) of five strawberry jams made from various sugar compositions. The jam containing the highest ratio of glucose showed a high GI, while that containing a high ratio of fructose, a jam made from polydextrose, showed a low GI. There was a high correlation $(r=0.969, p=0.006)$ between the GI and the predicted GI calculated from the sugar composition of the jams. Moreover, the influence on postprandial blood glucose response after an intake of only $20 \mathrm{~g}$ of jam and one slice of bread with $20 \mathrm{~g}$ jam was measured in 8 healthy adults. The blood glucose level after an intake of $20 \mathrm{~g}$ of the high GI jam containing the high glucose ratio was higher than that of other jams at $15 \mathrm{~min}$, but there was no significant difference after $30 \mathrm{~min}$. Regardless of whether the GI was low or high, differences in the jams were not observed in the postprandial blood glucose level or the area under the curve after eating either one slice of bread $(60 \mathrm{~g})$ or one slice of bread with less than $20 \mathrm{~g}$ of jam.
\end{abstract}

Key Words jam, bread, glycemic index (GI), glycemic load (GL), blood glucose

There is a worldwide increase these days in the number of patients with diabetes, a typical lifestyle-related disease. In Japan, the number of people strongly suspected to be diabetic or pre-diabetic can be estimated to be about 18.7 million (1).

The importance of managing the postprandial blood glucose response is increasing. Recent work has suggested that such factors as the form of food, the content of dietary fiber, and the amount of protein, lipids and available carbohydrates influence the postprandial blood glucose response (2-4). Different starchy foods produce different glucose and insulin responses when eaten individually (5).

Jenkins et al. (2) introduced the concept of the glycemic index (GI) as a way to rank foods according to their postprandial impact on the plasma glucose level. The GI value of over 750 foods has since been determined (6, 7). Many researches have reported the GI value of baked items, bread, and cereal products, but there are few studies on jam or spreads. Foster-Powell et al. reported the GI value of strawberry jam (7) but did not describe the sugar composition of strawberry jam that impacts the GI.

Eaten with bread, jam, a delicious preserved food made from sugar boiled with fruit, has been loved for many years. However, because its sweetness is strong, in recent years low-sugar content jam that suppresses the sweetness has accounted for approximately half the

\footnotetext{
${ }^{*}$ To whom correspondence should be addressed.
}

E-mail: kimiaki_fukuhara@aohata.co.jp
Japanese market. In addition, jam in which various saccharides are combined as a substitute for sugar-e.g., jam that uses fruit juice or low calorie maltitol syrupis now on market.

Wolever et al. determined the GI value of ten fruits and fruit products in patients with diabetes, comparing these foods with the GI of white bread $(\mathrm{GI}=100)$. In addition, they studied the predicted GI estimated from the sugar composition of the fruits. However, they provided no data about jam (8).

In the present study, we determined the GI value of five strawberry jams that used different saccharides. We evaluated the correlation between their sugar-composition and the observed GI. This strawberry jam accounted for approximately half the Japanese market. Recently, corn syrup, glucose, a sugar alcohol and fruit juice have been used in jam products.

Moreover, we investigated the influence on the postprandial blood glucose response after the intake of only $20 \mathrm{~g}$ of jam and also of bread with $20 \mathrm{~g}$ of jam. Jenkins et al. (9) reported the GI from a meal containing $50 \mathrm{~g}$ of carbohydrate from wholemeal bread, butter and marmalade. However, this is not the quantity of jam eaten in the general-diet. As a Japanese meal, we prepared one slice of bread and $20 \mathrm{~g}$ of jam.

Both the quantity and quality of carbohydrates in a meal influence the glycemic response. These variables are represented by the glycemic load (GL) (10). We calculated the GL of jam and considered its influence.

In this paper, we report the GI value of Japanese strawberry jam and the influence of a meal of bread and 
Table 1. Free sugar composition of strawberry jam and predicted glycemic index, and weight of the test meals in Experiment 1.

\begin{tabular}{|c|c|c|c|c|c|c|c|c|c|c|c|}
\hline \multirow{2}{*}{ Test meal } & \multicolumn{6}{|c|}{ Free sugar composition $\mathrm{g} /$ carbohydrate $50 \mathrm{~g}$} & \multirow{2}{*}{$\begin{array}{c}\text { Predicted } \\
\text { GI }\end{array}$} & \multicolumn{4}{|c|}{ Weight of the test meal $(\mathrm{g})$} \\
\hline & Sucrose & Fructose & Glucose & Sorbitol & $\mathrm{G} 2 \leqq *$ & $\begin{array}{c}\text { Dietary } \\
\text { fiber }\end{array}$ & & Jam & Water & $\begin{array}{l}\text { Amount } \\
\text { fed }\end{array}$ & $\begin{array}{l}\text { Carbo- } \\
\text { hydrate }\end{array}$ \\
\hline Jam S & 24.0 & 12.4 & 12.1 & N.D & N.D & 1.1 & 61 & 75 & 175 & 250 & 50 \\
\hline Jam CS & 14.0 & 5.7 & 14.8 & N.D & 10.8 & 0.7 & 73 & 87 & 163 & 250 & 50 \\
\hline Jam SG & 16.8 & 7.2 & 14.1 & N.D & 7.1 & 1.6 & 68 & 107 & 143 & 250 & 50 \\
\hline Jam J & 3.4 & 24.7 & 14.7 & 2.4 & N.D & 2.8 & 46 & 147 & 103 & 250 & 50 \\
\hline Jam PD & 0.0 & 1.6 & 1.3 & 2.9 & 2.5 & 37.0 & 9 & 115 & 135 & 250 & $50^{* *}$ \\
\hline
\end{tabular}

${ }^{*} \mathrm{G} 2 \leqq$ oligosaccharide more than maltose.

** Available carbohydrate+dietary fiber.

jam on the postprandial blood glucose response.

\section{Materials and Methods}

Experimental design. In Experiment 1, the GI value of five strawberry jams (Table 1) made from various sugar compositions was determined in 30 healthy subjects (20 women and 10 men), who were excluded if they were being treated for diabetes. These subjects had an average age of $29.4 \pm 11.7$, height of $163.1 \pm 8.5 \mathrm{~cm}$, weight of $57.8 \pm 10.9 \mathrm{~kg}$, and BMI of $21.6 \pm 2.7 \mathrm{~kg} / \mathrm{m}^{2}$ (mean \pm SD). Each subject took the 5 strawberry jams on separate mornings in a cross-over design. Subjects were asked to fast for at least $12 \mathrm{~h}$ before testing. Nothing was allowed to be eaten or drunk except water. On the test morning, the subjects had their fasting blood measured before consumption of the test meal. All subjects took a $50 \mathrm{~g}$ carbohydrate load of reference food (glucose: $50 \mathrm{~g}$ ) and the test meal (Table 1) within $5 \mathrm{~min}$. A subject who took more than one test meal had at least $2 \mathrm{~d}$ of a wash-out period before another food testing. A capillary blood glucose measurement was performed using a self-administered blood measuring device (Glutestase R, Sanwa Chemical Research Institute Co. Inc.). The subjects carried out self-monitoring of blood glucose measurement a total of seven times: during the fast, and at 15, 30, 45, 60, 90, and $120 \mathrm{~min}$ after loading. The incremental area under the curve (IAUC) of each test meal and the IAUC of reference glucose were calculated by each subject. The experiment was based on the method of Wolever et al. (11).

Moreover, in Experiment 1 we studied the correlation between the significant observed and predicted GI. The predicted GI was calculated as follows: (Ps $\times$ GIs $+\mathrm{Pf} \times$ GIf $+\mathrm{Pg} \times \mathrm{GIg}+\mathrm{Pso} \times \mathrm{Gso}+\mathrm{Pg} 2 \times \mathrm{Gg} 2) / 100$, where $\mathrm{P}$ is the percentage content of sucrose (s), fructose (f), glucose (g), sorbitol (so), and oligosaccharide more than maltose (g2), and GI is the GI of the respective sugars $(8)$. The GI values used for sucrose $(\mathrm{GI}=65)$, fructose $(\mathrm{GI}=23)$, glucose $(\mathrm{GI}=100)$, sorbitol $(\mathrm{GI}=9)$, and above the maltose $(\mathrm{GI}=105)$ were means from the literature quoted by Foster-Powell and Brand-Miller (6).

In Experiment 2, the influence on the postprandial blood glucose response after an intake of only $20 \mathrm{~g} \mathrm{jam}$, only one slice of bread $(60 \mathrm{~g})$, or one slice of bread with $20 \mathrm{~g}$ jam were measured for eight healthy non-diabetic
Table 2. Portion size of white bread and strawberry jam in Experiment 2.

\begin{tabular}{|c|c|c|c|c|c|}
\hline & $\begin{array}{c}\text { Bread } \\
\text { (g) }\end{array}$ & $\begin{array}{l}\text { Jam } \\
\text { (g) }\end{array}$ & $\begin{array}{c}\text { Water } \\
(\mathrm{g})\end{array}$ & $\begin{array}{l}\text { Amount } \\
\text { fed } \\
(\mathrm{g})\end{array}$ & $\begin{array}{c}\text { Total } \\
\text { carbohydrate } \\
\text { (g) }\end{array}$ \\
\hline Jam SG & - & 20 & 200 & 220 & 9.4 \\
\hline Jam J & - & 20 & 200 & 220 & 6.8 \\
\hline Jam MT & - & 20 & 200 & 220 & 13.4 \\
\hline Bread & 60 & - & 200 & 260 & 26.9 \\
\hline Bread+Jam SG & 60 & 20 & 200 & 280 & 36.3 \\
\hline Bread+Jam J & 60 & 20 & 200 & 280 & 33.7 \\
\hline Bread+Jam MT & 60 & 20 & 200 & 280 & 40.4 \\
\hline
\end{tabular}

adult men. These subjects had an average age of $42.4 \pm$ 4.8 , height of $173.4 \pm 7.5 \mathrm{~cm}$, weight of $70.0 \pm 8.7 \mathrm{~kg}$, and BMI of $23.3 \pm 2.6 \mathrm{~kg} / \mathrm{m}^{2}$. All subjects took the test meal (Table 2) within $5 \mathrm{~min}$. The measurement of the blood glucose level was by the same method used in Experiment 1.

This study was conducted with the approval of the committee of Showa Women's University in accordance with the concept of the Helsinki Declaration, and had written consent of all subjects after an explanation of the contents and method of study.

Test meals. The reference diet in Experiment 1 was a glucose solution that combined $50 \mathrm{~g}$ glucose and $200 \mathrm{~g}$ water. We bought four jams from the local supermarket: one made with sugar (S), a second made with corn syrup and sugar (CS), a third made with sugar and glucose (SG), and a fourth made with apple juice (J). We also created a strawberry jam (PD) $(40 \%$ polydextrose, $50 \%$ strawberry) in our laboratory which used polydextrose (Litesse III: Danisco A/S) from dietary fiber instead of sugar. The free sugar composition of strawberry jam containing $50 \mathrm{~g}$ carbohydrate and the predicted GI is shown in Table 1.

Each test diet contained $50 \mathrm{~g}$ of carbohydrate. For example, $75 \mathrm{~g}$ of jam S (50 g of carbohydrate) and $175 \mathrm{~g}$ of water ( $0 \mathrm{~g}$ carbohydrate) were given as one test meal item (Table 1). Only $20 \mathrm{~g}$ jam, only one slice of bread $(28.3 \mathrm{~g}$ carbohydrate, $5.0 \mathrm{~g}$ protein, $1.6 \mathrm{~g}$ fat, $0.8 \mathrm{~g}$ ash), and one slice of bread with $20 \mathrm{~g}$ jam were 


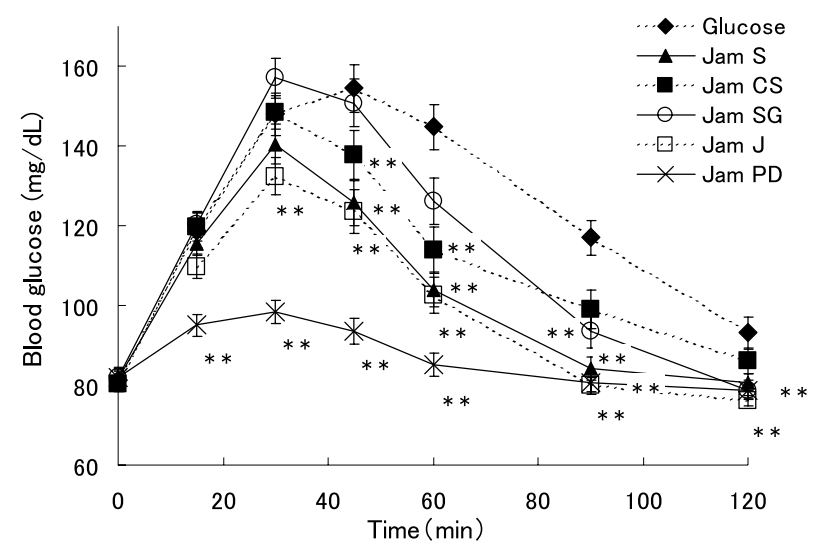

Fig. 1. Postprandial blood glucose level after 30 subjects consumed five strawberry jams. Each value expressed as mean \pm SE of subjects. ${ }^{* *} p<0.01$ indicates a significant difference from glucose. Results of GI value: glucose $=100$, jam $S=51$, jam $C S=74$, jam $S G=$ 70 , jam $\mathrm{j}=47$, jam $\mathrm{PD}=17$.

examined in Experiment 2. The typical weight of one slice of bread in the Japanese market is $60 \mathrm{~g}$. We used $20 \mathrm{~g}$ each of the strawberry jam SG, the jam J, and the low calorie strawberry jam (MT) made with maltitol syrup. Maltitol syrup is sugar alcohol and is low calorie (12). The glycemic load was calculated as the quantity of a jam's carbohydrate content multiplied by its GI and divided by 100 .

Statistical analysis. All measurements were expressed as mean \pm SE. Analysis of the data was carried out with SPSS, Ver 14.0 J. $p<0.05$ was considered significant. The GI values were subjected to ANOVA with the significance of difference between the means assessed by Dunnett multiple comparisons. The significance of differences between the postprandial blood glucose level for each strawberry jam and for white bread was assessed by the paired $t$ test. In addition, Pearson's correlation coefficient of the predicted GI and the observed GI was calculated.

\section{Results}

\section{Experiment 1}

The blood glucose response curves for $2 \mathrm{~h}$ after the intake of each strawberry jam that contained $50 \mathrm{~g}$ of carbohydrate are shown in Fig. 1. The blood glucose level at 45, 60 and 90 min after the intake of jam CS and at 90 min after the intake of jam SG were significantly lower than the reference glucose level. The significant points were 45, 60 and $90 \mathrm{~min}$ for jam S made from sugar and 30, 45, 60, 90 and 120 min for jam J made from the apple juice concentrate. The GI level for jam PD at all times was lower than that of the other levels measured except for the fasting blood glucose level.

According to Brand-Miller et al. (13), a low-GI food is defined as having a GI $\leqq 55$, and a high-GI food has a GI $\geqq 70$. Jam SG $(\mathrm{GI}=70)$ is classified therefore as high-GI. Jam CS, with a high content ratio of glucose, shows a high GI $(\mathrm{GI}=76)$. Jam $S$ and jam J, with a high content ratio of fructose, shows a low GI $(\mathrm{GI}=51,47)$. In addi-

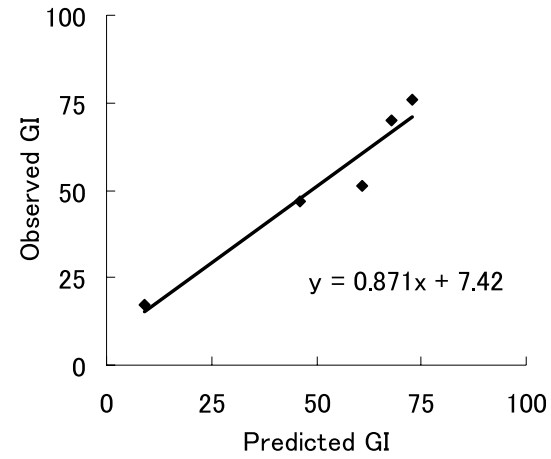

Fig. 2. Relationship between predicted (Table 1) and observed glycemic index values of the strawberry jams $(r=0.969, p=0.006)$.
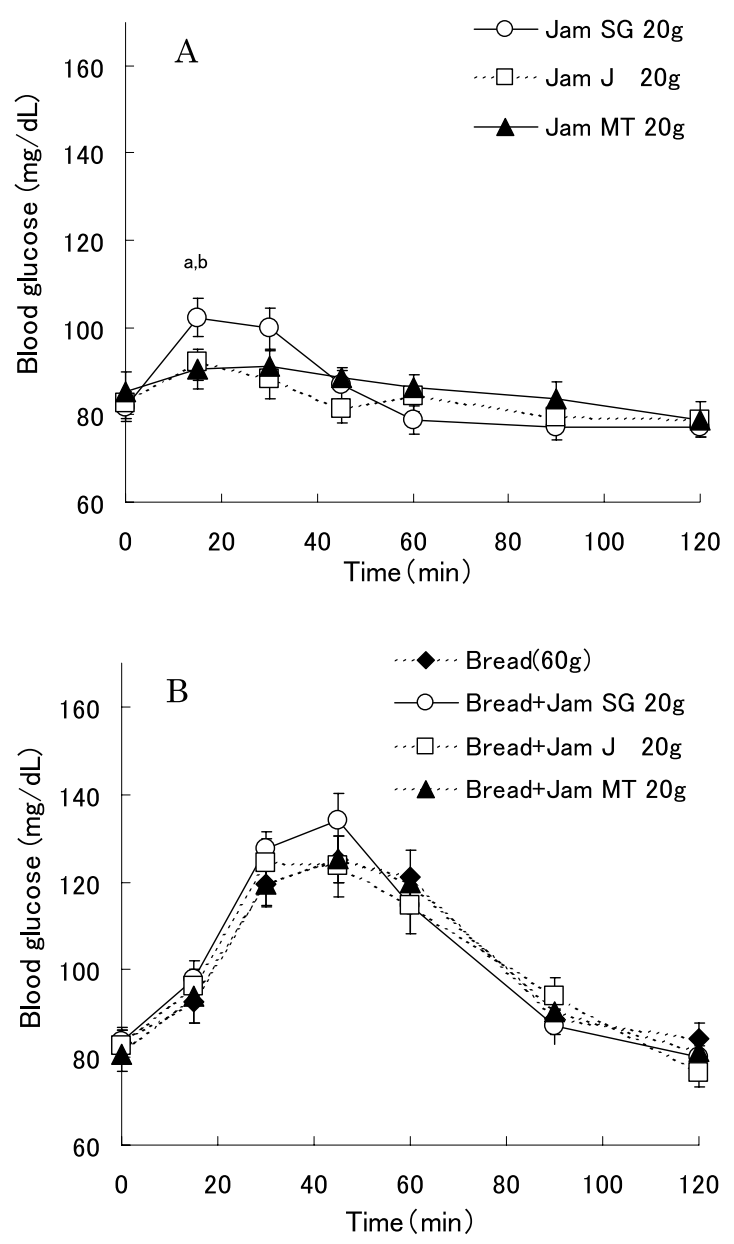

Fig. 3. Postprandial blood glucose level after subjects consumed $20 \mathrm{~g}$ of strawberry jam (A), and bread only and bread with jam (B). Results of IAUC: jam SG, 666 \pm 127 ; jam J, 356 \pm 66 ; jam MT, 484 \pm 190 ; bread,

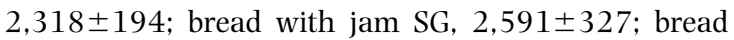

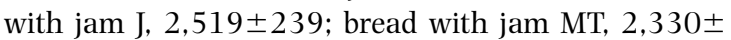
$301(\mathrm{mg} \cdot \mathrm{min} \cdot \mathrm{dL}){ }^{\mathrm{a}, \mathrm{b}} p<0.05$ indicates a significant difference from jam $\mathrm{J}$ and MT.

tion, jam PD, with a high content ratio of dietary fiber, shows a very low GI $(\mathrm{GI}=17)$.

The calculated result of the correlation between the observed GI and the predicted GI is significant $(r=$ 0.969, $p=0.006$ ) (Fig. 2). 


\section{Experiment 2}

After an intake of only $20 \mathrm{~g}$ of jam, jam SG showed a higher GI than jam J and jam MT in glucose level at $15 \mathrm{~min}$, but after $30 \mathrm{~min}$ there was no significant difference (Fig. 3A). However, we could not observe a difference in the blood glucose level at $15 \mathrm{~min}$ after the intake of one slice of bread, while the bread with jam SG which showed a higher value at $15 \mathrm{~min}$ (Fig. 3B). There was no difference in the IAUC after intake between one slice of bread only and the bread with jam SG. The IAUC after the intake of the bread with jam J or jam MT was the same as that after one slice of bread.

\section{Discussion}

In this study, we determined GI values in 30 healthy adults of five strawberry jams made with various sugar compositions. The results showed that the sugar composition changed the GI value of strawberry jam. Foster-Powell and Brand-Miller (6) reported the GI values of carbohydrate, fructose $(\mathrm{GI}=23)$, disaccharide $(\mathrm{GI}=105)$, sucrose $(\mathrm{GI}=65)$, and sorbitol $(\mathrm{GI}=9)$ based on glucose (100). Wolever et al. (8) determined the GI values of ten fruits and fruit products in diabetics for comparison with the GI of white bread (100). A fruit cocktail with a $44 \%$ content ratio of glucose showed $\mathrm{GI}=79$. Apple juice with a $63 \%$ content ratio of fructose showed GI $=59$. Their study suggested that the GI values were related to the fructose and glucose ratio. The correlation between the observed and predicted GI was significant $(r=0.684)$. In our results, jam CS with a $52.6 \%$ content ratio of maltose and glucose from corn syrup and glucose syrup showed a high GI (=76). Jam J with a $49.4 \%$ content ratio of fructose from apple juice concentrate showed a low GI $(=47)$. We confirmed that the relationship was significant $(r=0.969)$ (Fig. 2). The reason for the high correlation shown in our study is suggested by healthy adults being tested with $250 \mathrm{~g}$ of similar forms of jam with an equivalent amount of food ingested. In these cases, however, the test foods were in different forms (raw fruit, dry fruit, juice or canned fruit in syrup) and in different amounts eaten, varying from 319 to $658 \mathrm{~g}$.

The GI of the strawberry jam PD, which used polydextrose as the sugar substitute, was very low $(\mathrm{GI}=17)$. Because polydextrose is a soluble dietary fiber, it is difficult to digest and therefore barely influenced the postprandial glucose level, so its GI value was very low $(=4)$ $(7,14)$.

Powell reported that strawberry jam had a $\mathrm{GI}=51$ (7). However, our results show different GI values from 17 to 76 . We clarified that the GI value could be predicted from the sugar composition.

We investigated the influence on the postprandial blood glucose response in eight healthy adults after the intake of only $20 \mathrm{~g}$ jam and of one slice of bread with $20 \mathrm{~g}$ jam. An influence on the postprandial glucose level was barely confirmed. In particular, the blood glucose response of jam J after intake did not rise rapidly for smaller amounts of carbohydrate $(6.8 \mathrm{~g})$, and the GI was low. Jam MT contained the most carbohydrates
(13.4 g) of the three kinds of strawberry jam, but the glucose response was mild because this jam was made with maltitol syrup (12).

Jenkins et al. compared glycemic responses by diabetics after the intake of only wholemeal bread and of wholemeal bread with butter and marmalade (containing $50 \mathrm{~g}$ of carbohydrate) (9). However, their study arranged for the carbohydrate quantity to be $50 \mathrm{~g}$, and the influence of the marmalade was not clear.

We assumed the meal was breakfast and examined the blood glucose response from one slice of bread and $20 \mathrm{~g}$ of jam. The amount of carbohydrate in one slice of bread was $26.9 \mathrm{~g}$ when the jam and bread totaled 33.7-40.4 g. However, there were no significant differences in the blood glucose level or IAUC between one slice of bread and one slice of bread with $20 \mathrm{~g}$ of strawberry jam.

This is attributed to the fact that the carbohydrate in $20 \mathrm{~g}$ of jam is $13.4 \mathrm{~g}$ in jam MT, $9.4 \mathrm{~g}$ in jam SG, and $6.8 \mathrm{~g}$ in jam J and to the GI value of the carbohydrates. The GI value of white bread was reported as 70 (7); we estimated the GL of the bread using this value. We consider that the GL of jam J $(\mathrm{GL}=3.2)$ and SG $(\mathrm{GL}=6.5)$ is smaller than that of one slice of bread $(G L=19.8)$. Since jam MT was made with maltitol syrup, we think that its GL is low.

When bread and jam are eaten together, the IAUC shows a value which is lower than the sum of the IAUC from eating only one slice of bread and the IAUC from eating only $20 \mathrm{~g}$ of jam. Wolever et al. examined the relationship between the glycemic load and the IAUC for white bread carbohydrate in quantities from 0 to $50 \mathrm{~g}$ (15). The dose response curve of IAUC for doses of carbohydrate was nearly linear over the range of $0-$ $20 \mathrm{~g}$ carbohydrate, but was significantly non-linear over the range of $0-50 \mathrm{~g}$ carbohydrate. The total carbohydrate of jam and the bread in this study was in the 33.7-40.4 g range. We considered that the IAUC was lower than estimated because the carbohydrate quantity was more than $20 \mathrm{~g}$.

This study confirmed that the blood glucose response did not rise rapidly after eating bread with jam. At present in this study, we have only investigated the glucose response of jams in healthy subjects; an evaluation of the insulin response remains to be done. Further studies of the postprandial blood glucose and insulin response in diabetics are also required.

We determined in healthy adults the GI values of five strawberry jams made from various sugar compositions. The present work shows that the GI value of strawberry jam ranges from 17 to 76 and is not constant. Regardless of whether there was a low or high GI, eating one slice of bread $(60 \mathrm{~g})$ with less than $20 \mathrm{~g}$ of strawberry jam did not have any significant influence on the postprandial blood glucose level or the area under the curve.

\section{REFERENCES}

1) NIHN. 2008. Outline for the results of the National Health and Nutrition Survey, Japan 2006. National 
Institute of Health and Nutrition [Online]. Available: http://www0.nih.go.jp/eiken/english/research/project_ nhns.html [accessed March 27, 2009].

2) Jenkins DJA, Wolever TMS, Taylor RH, Barker H, Fielden H, Baldwin JM, Bowling AC, Newman HC, Jenkins AL, Goff DV. 1981. Glycemic index of foods: a physiological basis for carbohydrate exchange. Am J Clin Nutr 34: 362-366.

3) Jenkins DJA, Thorne MJ, Camelon K, Jenkins A, Rao AV, Taylor RH, Thompson LU, Kalmusky J, Reichert R, Francis T. 1982. Effect of processing on digestibility and the blood glucose response: a study of lentils. Am J Clin Nutr 36: 1093-1101.

4) Jenkins DJA, Wolever TMS, Jenkins AL, Josse RG, Wong GS. 1984. The glycaemic response to carbohydrate foods. Lancet 2: 388-391.

5) Jenkins DJA, Wolever TMS, Jenkins AL. 1988. Starchy foods and the glycemic index. Diabetes Care 11: 149159.

6) Foster-Powell K, Brand-Miller J. 1995. International tables of glycemic index. Am J Clin Nutr 62: 871S-890S.

7) Foster-Powell K, Holt SHA, Brand-Miller J. 2002. International table of glycemic index and glycemic load values. Am J Clin Nutr 76: 5-56.

8) Wolever TMS, Vuksan V, Relle LK, Jenkins AL, Josse RG, Wong GS, Jenkins DJA. 1993. Glycemic index of fruits and fruit products in patients with diabetes. Int J Food Sci Nutr 43: 205-212.
9) Jenkins DJA, Wolever TMS, Jenkins AL, Thorne MJ, Lee R, Kalmusky J, Reichert R,Wong GS. 1983. The glycemic index of foods tested in diabetic patients: A new basis for carbohydrate exchange favouring the use of legumes. Diabetologia 24: 257-264.

10) Salmeron J, Manson JE, Stampfer MJ, Colditz GA, Wing AL, Willett WC. 1997. Dietary fiber, glycemic load, and risk of non-insulin-dependent diabetes mellitus in women. J Am Med Assoc 277: 472-477.

11) Wolever TMS, Jenkins DJ, Jenkins AL, Josse RG. 1991. The glycemic index: methodology and clinical implications. Am J Clin Nutr 54: 846-854.

12) Secchi A, Pontiroli AE, Cammelli L, Bizzi A, Cini M, Pozza G. 1986. Effects of oral administration of maltitol on plasma glucose, plasma sorbitol, and serum insulin levels in man. Klinische Wochenschrift 64: 265-269.

13) Brand-Miller J, Wolever TMS, Colagiuri S, Foster-Powell K. 1999. The new glucose revolution. Marlowe \& Company, New York.

14) Achour L, Flourié B, Briet F, Pellier P, Marteau P, Rambaud JC. 1994. Gastrointestinal effects and energy value of polydextrose in healthy nonobese men. Am J Clin Nutr 59: 1362-1368.

15) Wolever TMS, Gibbs AL, Spolar M, Hitchner EV, Heimowitz C. 2006. Equivalent glycemic load (EGL): a method for quantifying the glycemic responses elicited by low carbohydrate foods. Nutr Metab (Lond) 3: 33. 